\title{
Sensitivity of US air quality to mid-latitude cyclone frequency and implications of 1980-2006 climate change
}

\author{
E. M. Leibensperger, L. J. Mickley, and D. J. Jacob \\ School of Engineering and Applied Sciences, Harvard University, Cambridge, Massachusetts, USA \\ Received: 22 May 2008 - Published in Atmos. Chem. Phys. Discuss.: 24 June 2008 \\ Revised: 29 September 2008 - Accepted: 29 October 2008 - Published: 6 December 2008
}

\begin{abstract}
We show that the frequency of summertime midlatitude cyclones tracking across eastern North America at $40^{\circ}-50^{\circ} \mathrm{N}$ (the southern climatological storm track) is a strong predictor of stagnation and ozone pollution days in the eastern US. The NCEP/NCAR Reanalysis, going back to 1948, shows a significant long-term decline in the number of summertime mid-latitude cyclones in that track starting in $1980\left(-0.15 \mathrm{a}^{-1}\right)$. The more recent but shorter NCEP/DOE Reanalysis (1979-2006) shows similar interannual variability in cyclone frequency but no significant long-term trend. Analysis of NOAA daily weather maps for 1980-2006 supports the trend detected in the NCEP/NCAR Reanalysis 1 . A GISS general circulation model (GCM) simulation including historical forcing by greenhouse gases reproduces this decreasing cyclone trend starting in 1980 . Such a long-term decrease in mid-latitude cyclone frequency over the 1980-2006 period may have offset by half the ozone air quality gains in the northeastern US from reductions in anthropogenic emissions. We find that if mid-latitude cyclone frequency had not declined, the northeastern US would have been largely compliant with the ozone air quality standard by 2001 . Midlatitude cyclone frequency is expected to decrease further over the coming decades in response to greenhouse warming and this will necessitate deeper emission reductions to achieve a given air quality goal.
\end{abstract}

\section{Introduction}

Regional pollution episodes in the eastern US develop under summertime stagnant conditions with clear skies, a situation associated with weak high-pressure systems (Logan, 1989;

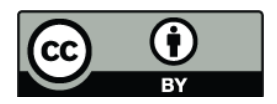

Correspondence to: E. M. Leibensperger (eleibens@fas.harvard.edu)
Vukovich, 1995; Hegarty et al., 2007). The pollution episode ends when the warm, stagnant air mass is pushed to the Atlantic by the cold front of a passing mid-latitude baroclinic cyclone and replaced with cooler, cleaner air (Merrill and Moody, 1996; Cooper et al., 2001; Dickerson et al., 1995; Li et al., 2005). We show here with 1980-2006 data that interannual variability in the frequency of these mid-latitude cyclones is a major predictor of the interannual variability of pollution episodes, as measured by indices for stagnation and elevated surface ozone. Greenhouse-driven climate change is expected to decrease mid-latitude cyclone frequency, and we present evidence that such a decrease may have already taken place over the 1980-2006 period. As we show, this would have major implications for pollution trends in the eastern US and significantly offset the benefits of decreasing anthropogenic emissions.

Figure 1 illustrates the role of mid-latitude cyclones in ventilating the eastern US with an example from the summer of 1988. That summer experienced the worst regional air quality of the 1980-2006 record (Lin et al., 2001). On 14 June, the daily maximum 8-h average ozone concentrations exceeded $100 \mathrm{ppb}$ across most of the region, a result of accumulation over several days of stagnant high-pressure conditions. Over the next two days, a mid-latitude cyclone moved along a westerly track across southeastern Canada. The associated cold front swept the pollution eastward to the North Atlantic, leaving much cleaner air with lower ozone concentrations in its wake. The westerly track across southeastern Canada illustrated in Fig. 1 is typical of mid-latitude cyclones traveling across North America. The frequency of these cyclones varies considerably from year to year (Zishka and Smith, 1980; Whittaker and Horn, 1981).

General circulation model (GCM) simulations of greenhouse-forced 21 st-century climate change indicate a poleward shift in the preferential storm tracks (Yin, 2005) and a decrease in the frequency of northern mid-latitude

Published by Copernicus Publications on behalf of the European Geosciences Union. 


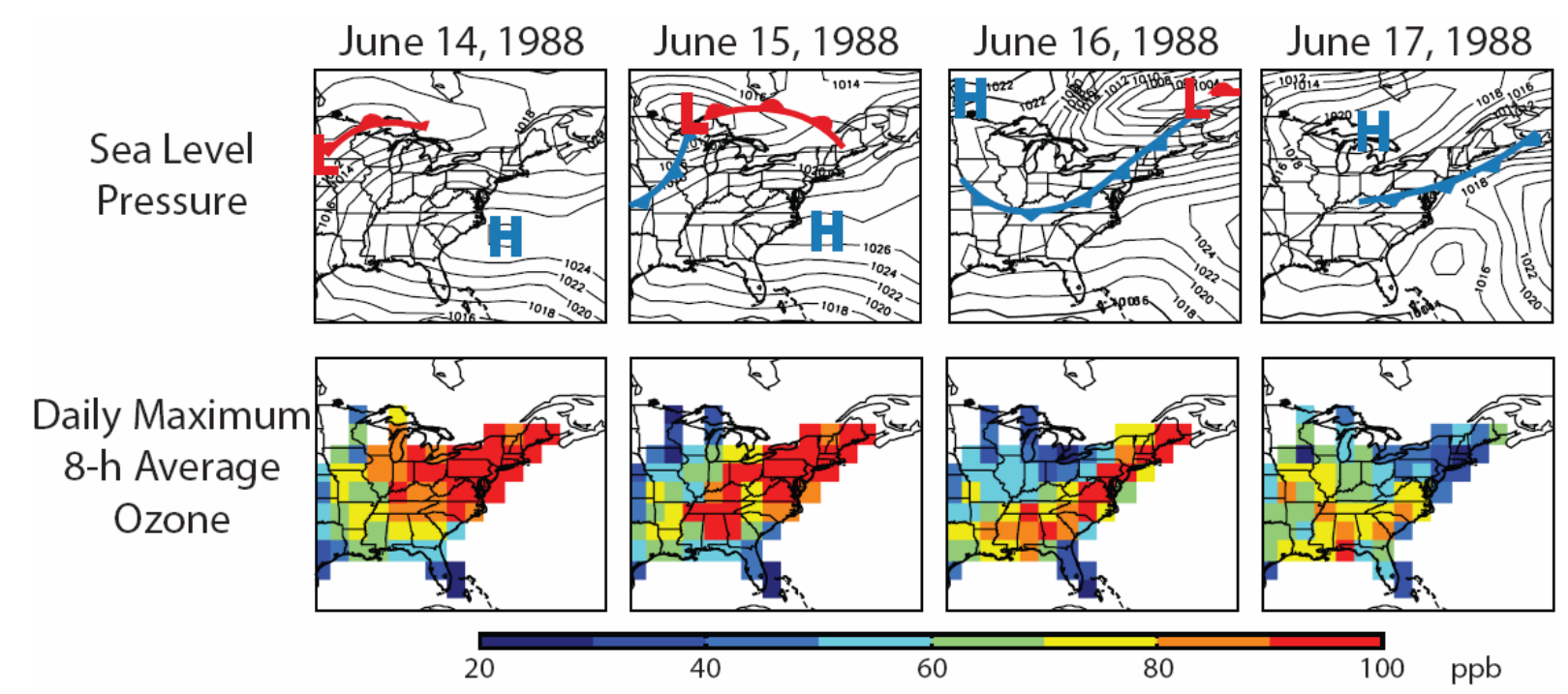

Fig. 1. Evolution of surface ozone concentrations in the eastern US during the passage of a mid-latitude cyclone (14-17 June 1988). The top row shows instantaneous sea-level pressure fields at $12 \mathrm{Z}$ from the NCEP/NCAR Reanalysis 1, while the bottom row shows daily maximum 8-h average ozone concentrations from monitoring sites of the US Environmental Protection Agency (http://www.epa.gov/ttn/airs/airsaqs/), The contour interval for sea level pressure is $2 \mathrm{hPa}$. The ozone data have been averaged on a $2.5^{\circ} \times 2.5^{\circ}$ grid.

cyclones (Geng and Sugi, 2003; Yin, 2005; Lambert and Fyfe, 2006; Meehl et al., 2007). These effects result from a shift and reduction of baroclinicity forced by weakened meridional temperature gradients (Geng and Sugi, 2003; Yin, 2005). One would expect an adverse effect on US air quality. A GCM simulation by Mickley et al. (2004) including pollution tracers found a $20 \%$ decrease in the frequency of summertime mid-latitude cyclones ventilating the US by 2050 and an associated increase in the frequency and intensity of pollution episodes. Two subsequent studies of US air quality in 21st-century climates, using global chemical transport models driven by GCM output, confirmed the increase of ozone pollution episodes due to decreased frequency of mid-latitude cyclones (Murazaki and Hess, 2006; Wu et al., 2008), but another study using a regional climate model did not (Tagaris, et al., 2007).

Decreasing trends in mid-latitude cyclones over the past decades have been identified in the observational record. A study by Zishka and Smith (1980) using observational weather maps for North America found a significant decrease of 4.9 cyclones per decade in July and 9.0 cyclones per decade in December for 1950-1977. Another study by Wang et al. (2006) using surface pressure data for 1953-2002 identified a significant decreasing trend in cyclone activity along eastern Canada during the winter. Similar trends have been found in studies using meteorological reanalyses (i.e., assimilated meteorological data). Gulev et al. (2001) found a decrease of 12.4 cyclones per decade in the Northern Hemisphere and 8.9 cyclones per decade over the Atlantic Ocean during winter 1958-1999. McCabe et al. (2001) found a significant decrease in cyclones at mid-latitudes $\left(30^{\circ}-60^{\circ} \mathrm{N}\right)$ and an increase at high-latitudes $\left(60^{\circ}-90^{\circ} \mathrm{N}\right)$ during winter 1959-1997. Previous studies have generally focused on winter, the season with the strongest climate change signal. In this study we focus on summer, which is of most interest from an air quality standpoint.

A large number of statistical studies have related air quality to local meteorological variables such as temperature, humidity, wind speed, or solar radiation, often with the goal of removing the effect of interannual meteorological variability in the interpretation of air quality trends (Zheng et al., 2007; Bloomfield et al., 1996; Thomspon et al., 2001; Camalier et al., 2007; Gégo et al., 2007). Ordóñez et al. (2005) found that the number of days since the last frontal passage was a significant predictor of ozone air quality in Switzerland. Hegarty et al. (2007) related the interannual frequency and intensity of sea level pressure patterns over eastern North America to ozone, $\mathrm{CO}$, and particulate matter concentrations. Mid-latitude cyclone frequency is an attractive meteorological predictor for air quality on several accounts. First, it encapsulates to some extent the information in the local meteorological predictors (temperature, solar radiation, wind speed), while additionally providing direct information on boundary layer ventilation. Second, it represents a non-local single metric to serve as explanatory variable for air quality on a regional scale. Third, since mid-latitude cyclones are an important aspect of the general circulation of the atmosphere, cyclone frequency can be expected to be robustly simulated by GCMs and thus provide a useful and general metric for probing the effect of climate change on air quality. 

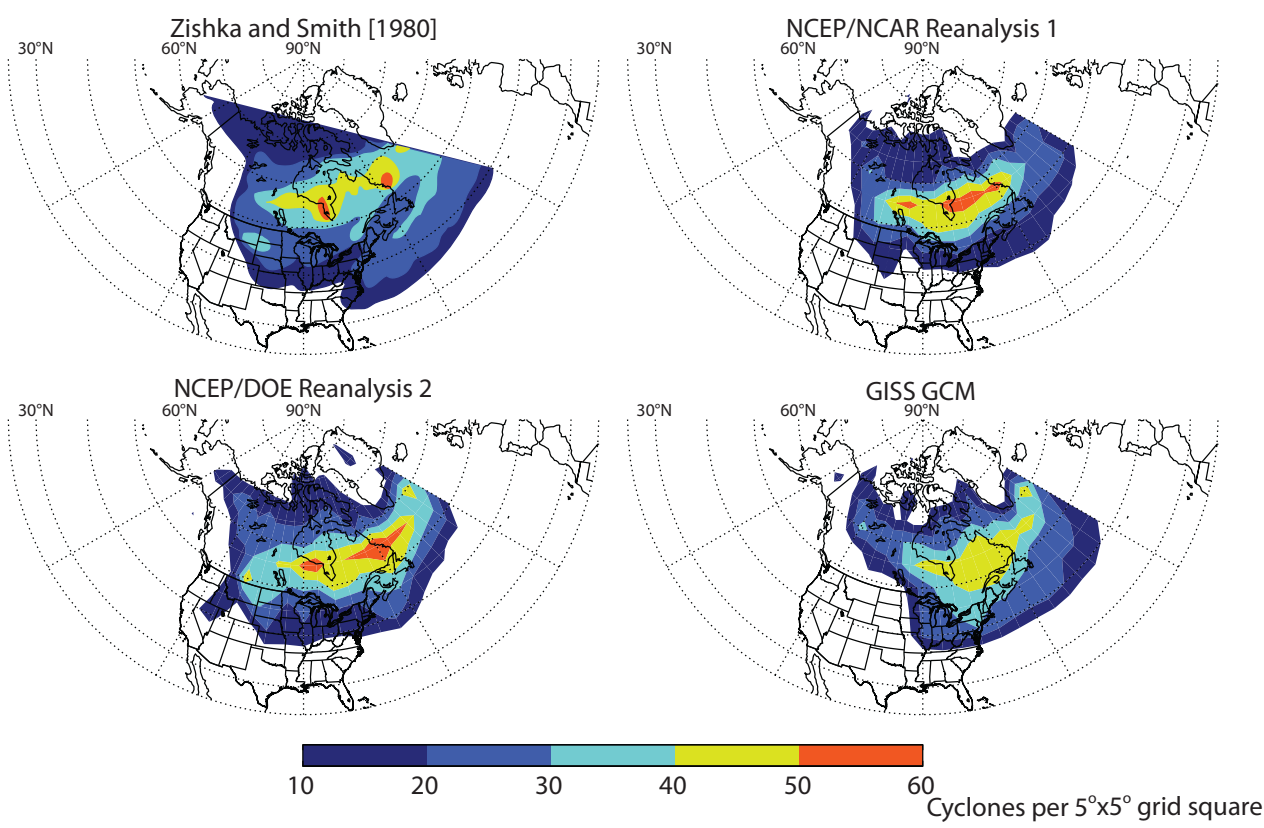

Fig. 2. 28-year July climatologies of cyclone tracks across North America, counting all cyclone tracks that pass through $5^{\circ} \times 5^{\circ}$ grid squares. The Zishka and Smith (1980) climatology is for 1950-1977 and based on monthly compilations of 6-h weather maps; the data shown here are adapted from their Fig. 3. The NCEP/NCAR Reanalysis 1 and NCEP/DOE Reanalysis 2 climatologies are for 1950-1977 and 1979-2006, respectively. The GISS GCM climatology is for 1950-1977 in a transient-climate simulation including historical trends in greenhouse gases and aerosols.

\section{Data and methods}

\subsection{Detection and tracking of mid-latitude cyclones}

Various metrics can be used to diagnose mid-latitude cyclone activity, including eddy kinetic energy (Hu et al., 2004), temporal variability of sea-level pressure, temperature or meridional wind (Harnik and Chang, 2003), the meridional temperature gradient, and the Eady growth rate (Paciorek et al., 2002). Some studies have used the probability distribution of sea-level pressure as a diagnostic of cyclone frequency (Murazaki and Hess, 2006; Lin et al., 2008; Racherla and Adams, 2008). A problem with these metrics for application to air quality is that they potentially convolve cyclone frequency and intensity, while air quality is most sensitive to cyclone frequency (i.e., the frequency of cold frontal passages). For example, Owen et al. (2006) found that both strong and weak warm conveyor belts effectively ventilate US pollution, although at different altitudes. In Sect. 3 we will show that mid-latitude cyclone is an excellent predictor of pollution episodes.

We constructed long-term cyclone frequency statistics for eastern North America in June-August using two different methods and three different data sets: (1) daily observed weather maps for 1980-2006 from the National Oceanic and Atmospheric Administration (NOAA) avail- able from the NOAA Central Library (http://www.lib.noaa. gov) with labeled cyclones and cold fronts; (2) sea-level pressure data from the National Centers for Environmental Prediction/National Center for Atmospheric Research (NCEP/NCAR) Reanalysis 1 (http://www.cdc.noaa.gov/cdc/ data.ncep.reanalysis.html) (Kalnay et al., 1996; Kistler et al., 2001) for 1948-2006 and from the NCEP/Department of Energy (NCEP/DOE) Reanalysis 2 (http://www.cdc.noaa.gov/ cdc/data.ncep.reanalysis2.html) (Kanamitsu et al., 2002) for 1979-2006. Reanalysis 2 is a newer version of Reanalysis 1 incorporating updated physical parameterizations and various error fixes, but it does not cover as long a period. The reanalysis datasets have a spatial resolution of $2.5^{\circ} \times 2.5^{\circ}$ and a temporal resolution of six hours. The previously mentioned studies of long-term mid-latitude cyclone trends (McCabe et al., 2001; Gulev et al., 2001; Geng and Sugi, 2001) all used Reanalysis 1 .

We generate cyclone tracks in the meteorological reanalyses by locating and following sea-level pressure minima following the algorithm of Bauer and Del Genio (2006), which is an upgraded version of the scheme by Chandler and Jonas (1999). For each 6-h time step the algorithm searches for sea-level pressure minima extending $720 \mathrm{~km}$ or more in radius. The low-pressure center is tracked through time by assuming that the strongest sea-level pressure minimum in the next 6-h time step within $720 \mathrm{~km}$ is the same system. In 
NCEP /NCAR Reanalysis 1

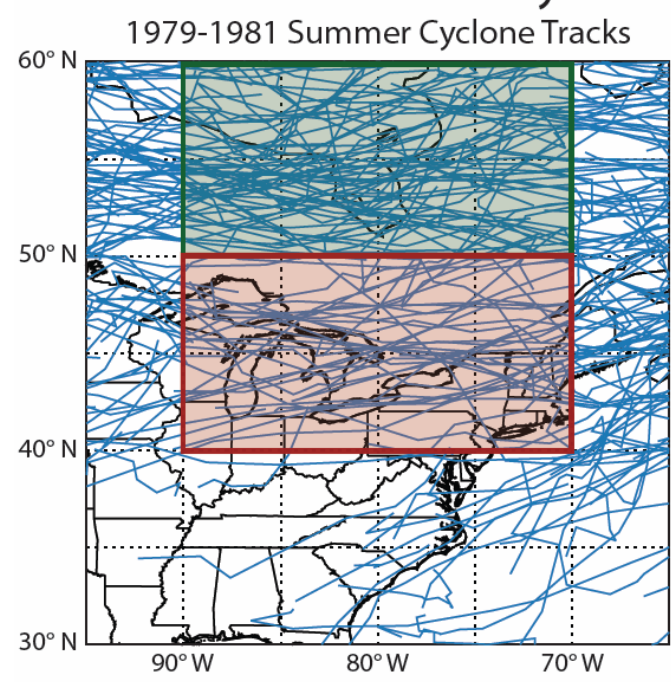

NCEP /DOE Reanalysis 2

1979-1981 Summer Cyclone Tracks

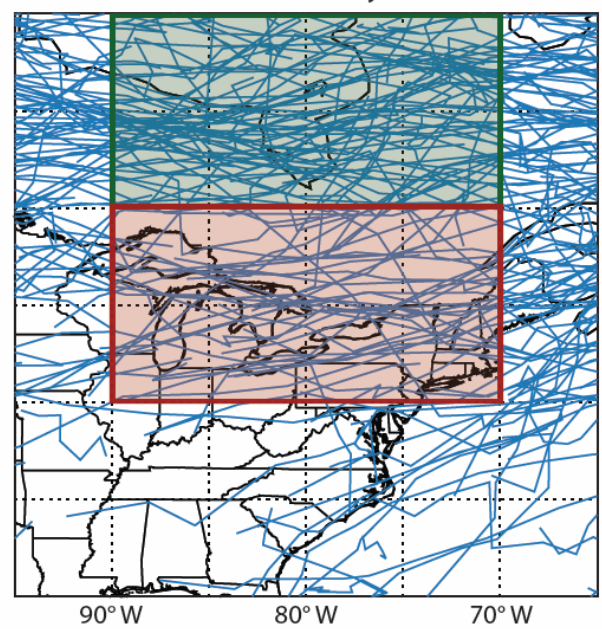

Fig. 3. Mid-latitude cyclone tracks for June-August 1979-1981 in the NCEP/NCAR Reanalysis 1 (left) and NCEP/DOE Reanalysis 2 (right). The red box $\left(70^{\circ}-90^{\circ} \mathrm{W}, 40^{\circ}-50^{\circ} \mathrm{N}\right)$ is used to diagnose the frequency of mid-latitude cyclones traveling along the southern climatological cyclone track. The green box $\left(70^{\circ}-90^{\circ} \mathrm{W}, 50^{\circ}-60^{\circ} \mathrm{N}\right)$ is used for the northern climatological cyclone tracks.

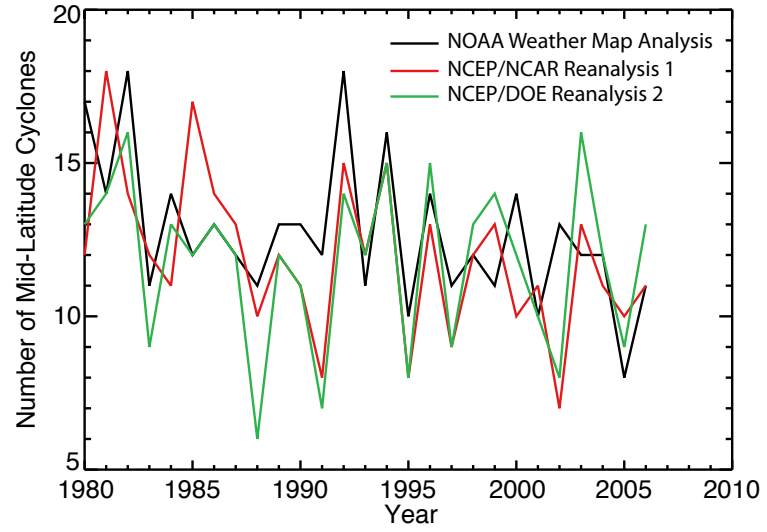

Fig. 4. June-August 1980-2006 time series of the number of midlatitude cyclones passing through the red box of Fig. 3, corresponding to the southern climatological cyclone track across North America. Results are shown for three different data sets: NOAA daily weather maps (black), NCEP/NCAR Reanalysis 1 (red) and NCEP/DOE Reanalysis 2 (green).

order to remove spurious minima, the system must be tracked for at least $24 \mathrm{~h}$ and have a central pressure no higher than $1020 \mathrm{hPa}$.

Figure 2 shows 28-year July climatologies of cyclone density over North America. The compilation of Zishka and Smith (1980) for 1950-1977, produced from 6-h weather maps, is compared to the climatologies produced by applying the algorithm of Bauer and Del Genio (2006) to Reanalysis 1 (1950-1977) and Reanalysis 2 (1979-2006). Patterns and magnitudes are in good agreement, showing that the cyclone tracking algorithm applied to the reanalysis data can reproduce the observed large-scale climatological distribution of mid-latitude cyclones. Inspection of 1979-2006 vs. 19501977 climatologies in Reanalysis 1 indicates no difference between these two periods in the large-scale cyclone patterns shown in Fig. 2, although there is a significant trend as discussed in Sect. 4.

We see from Fig. 2 that cyclone density is maximum over east-central Canada, corresponding to the two northern climatological cyclone tracks across North America previously identified by Zishka and Smith (1980) and Whittaker and Horn (1981). These studies also identified a less intense southern climatological track that begins in the central US and moves northeastward along the US-Canada border before merging with the northern tracks along the east coast of Canada. As we will see, it is this southern climatological track that is of most interest for US air quality.

Figure 3 shows individual cyclone tracks for June-August 1979-1981 over eastern North America in Reanalyses 1 and 2. A cluster over the Great Lakes region represents the southern climatological cyclone track. We will show in Sect. 3 that the frequency of cyclones moving along this track, identified by the red box $\left(70^{\circ}-90^{\circ} \mathrm{W}, 40^{\circ}-50^{\circ} \mathrm{N}\right)$, is a strong seasonal predictor of the frequency of US pollution episodes. By contrast, we find that the number of cyclones passing through the northern climatological tracks $\left(70^{\circ}-90^{\circ} \mathrm{W}, 50^{\circ}-60^{\circ} \mathrm{N}\right.$, green box in Fig. 3) is not a successful predictor. We focus on the southern track in the rest of this paper. 
NCEP /NCAR Reanalysis 1

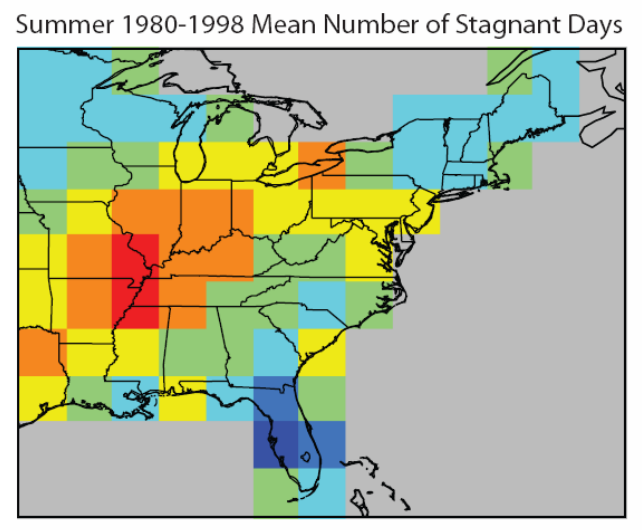

NCEP /DOE Reanalysis 2

Summer 1980-1998 Mean Number of Stagnant Days

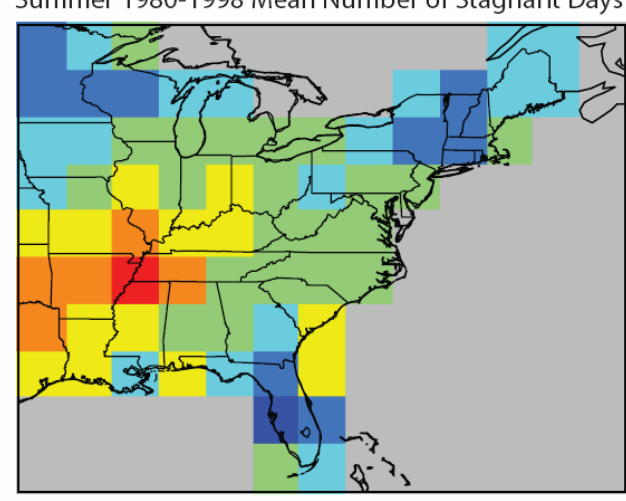

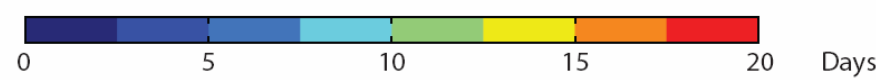

Fig. 5. Seasonal mean number of June-August stagnant days in the 1980-1998 records from NCEP/NCAR Reanalysis 1 (left) and NCEP/DOE Reanalysis 2 (right).

Figure 4 shows the time series of the 1980-2006 summertime frequency of mid-latitude cyclones in the southern climatological cyclone track (number of cyclones tracking through $70-90^{\circ} \mathrm{W}, 40-50^{\circ} \mathrm{N}$ ) from Reanalyses 1 and 2 as well as from our manual analysis of the NOAA weather maps. We tallied a system as a cyclone in the NOAA weather maps if it was marked as a "Low" on the map, contained a closed sea-level pressure contour, and was tracked for at least $24 \mathrm{~h}$. The three datasets have comparable climatological statistics $\left(11.9 \pm 2.6\right.$ cyclones summer ${ }^{-1}$ in Reanalysis $1,11.8 \pm 2.7$ in Reanalysis $2,12.7 \pm 2.4$ in NOAA weather maps). Reanalysis 1 and the NOAA weather maps show a significant decreasing trend for 1980-2006 but Reanalysis 2 does not. We discuss these long-term trends in Sect. 4.

Figure 4 shows strong interannual correlations between cyclone frequencies diagnosed from the three different data sets but also significant differences. Inspection of these differences for individual years shows that although the diagnosis of cyclones in Reanalyses 1 and 2 generally follows the cyclone identification in the daily weather maps, there are some differences in the intensity and position of the sea-level pressure minima for the three different data sets. These differences can result in displacement of the cyclone relative to the red box in Fig. 3 used to identify the southern climatological track, and can occasionally affect cyclone detection. Cyclone identification using the NOAA weather maps is closest to the actual observations but is subject to case-by-case human interpretation. The cyclone tracking algorithm applied to the meteorological reanalyses is more objective and can be applied to GCM fields (Sect. 4), but it is subject to errors both in the reanalyses and in the tracking algorithm. We will use the three datasets to overcome these problems in the reanalysis and weather map analyses.

\subsection{Detection of stagnation episodes}

We use stagnation frequency as a link to better understand the correlation between cyclone frequency and pollution events. The number of stagnant days was calculated from Reanalyses 1 and 2 data for June-August 1980-1998 with the metric described by Wang and Angell (1999), which is similar to the original version by Korshover and Angell (1982). A day is considered stagnant if the daily mean sea-level pressure geostrophic wind is less than $8 \mathrm{~m} \mathrm{~s}^{-1}$, the daily mean $500 \mathrm{hPa}$ wind is less than $13 \mathrm{~m} \mathrm{~s}^{-1}$, and there is no precipitation. Precipitation was identified with daily gridded data $\left(0.25^{\circ} \times 0.25^{\circ}\right)$ from the NOAA Climate Prediction Center (http://www.cdc.noaa.gov/cdc/data.unified.html) extending to 1998. For our purposes, the $1980-1998$ period is sufficient to show the relationship between stagnation and ozone episodes. Figure 5 shows the mean number of stagnant days per summer for 1980-1998 from Reanalyses 1 and 2. The frequency of stagnant days in both datasets is highest in a band stretching from Texas to Ohio, as previously shown by Wang and Angell (1999).

\subsection{Surface ozone data}

We generated time series of daily maximum 8-h average ozone concentrations for June-August 1980-2006 from hourly observations of ozone concentrations retrieved from EPA's Air Quality System (AQS, http://www.epa.gov/ttn/ airs/airsaqs/), representing a network of over 2000 sites in the contiguous US. The average number of sites providing ozone data since 1980 is about 1000 per summer; this number has increased over time. The daily maximum 8 -h average ozone concentrations from all AQS sites were averaged onto the $2.5^{\circ} \times 2.5^{\circ}$ grid of the NCEP Reanalyses, producing a daily 


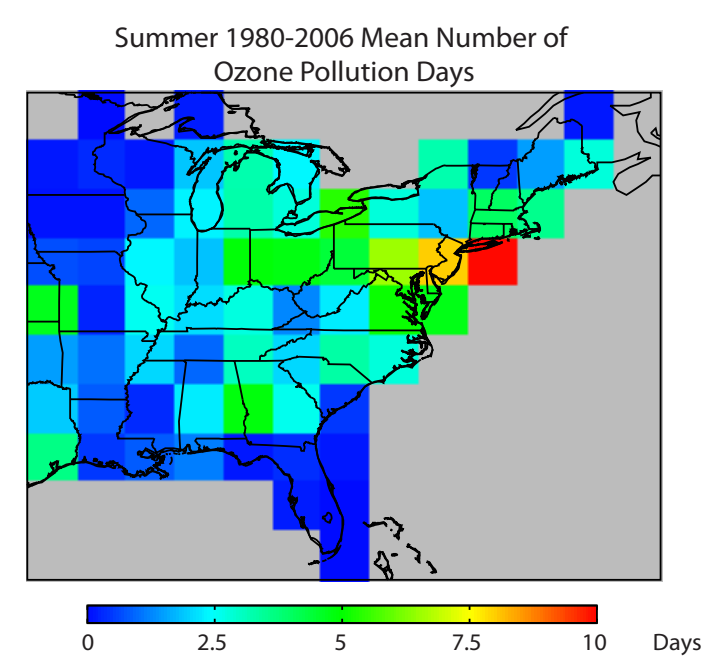

Fig. 6. Seasonal average number of June-August ozone pollution days for the 1980-2006 period. A pollution day occurs when the mean daily maximum 8 -h average ozone concentration averaged over observational sites within a $2.5^{\circ} \times 2.5^{\circ}$ grid square is greater than $84 \mathrm{ppb}$.

time series for 1980-2006 (Fig. 1 was produced from that time series). The number of days with a daily maximum 8-h average ozone concentration greater than $84 \mathrm{ppb}$ was tallied for each summer, creating a 27 -year time series of the seasonal number of ozone pollution days for each grid square corresponding to an exceedance of the $0.08 \mathrm{ppm}$ US air quality standard. Spatial averaging causes an underestimate of the number of ozone pollution days, but enhances statistical robustness by removing data extremes and improving continuity. Spatial averaging also enables comparison to the identically gridded reanalysis products. Not every grid square included measurements for all 27 years. A grid square was analyzed only if it had 5 or more years of data.

Figure 6 shows the mean number of summertime ozone pollution episodes for $1980-2006$ on the $2.5^{\circ} \times 2.5^{\circ}$ grid. The highest values ( $>6$ days) are in the New York CityWashington, DC corridor, but high values (2-6 days) extend over much of the industrial Midwest and Northeast, and in some areas of the Southeast.

\subsection{GCM simulations}

We conducted two simulations with the Goddard Institute for Space Studies (GISS) GCM 3 (Rind et al., 2007) to investigate the effect of 1950-2006 climate change on mid-latitude cyclone frequencies. The first simulation was conducted for 1950-2006 using reconstructed time-dependent concentrations of greenhouse gases, aerosol forcing, and solar radiation (Hansen et al., 2002). The second (control) simulation was conducted in radiative equilibrium (greenhouse gas and aerosol concentrations were held at their 1950 levels), also for 1950-2006. The GCM has a horizontal resolution of $4^{\circ}$ latitude $\times 5^{\circ}$ longitude and 23 vertical layers extending from the surface to $0.002 \mathrm{hPa}$ in a sigma-pressure coordinate system (Rind et al., 2007). It uses a "qflux" representation for ocean heat transport (Hansen et al., 1988), which allows temporal variation in sea surface temperature and sea ice, but holds constant the horizontal heat transport fluxes in the ocean to values derived from present-day sea surface temperature distributions.

Mid-latitude cyclones are detected and tracked from the GCM sea-level pressure output with the same algorithm used for the reanalysis data (Sect. 2.1). The GCM cyclone climatology for 1950-1977 (1979-2006 shows the same climatological patterns) is compared to the observational and reanalyses data in Fig. 2. Agreement is excellent. The number of GCM cyclones passing through the southern climatological track (red box in Fig. 3) is 10.8 \pm 2.4 per summer for the 1980-2006 period, consistent with the reanalyses (Sect. 2.1).

\section{Mid-latitude cyclones as predictors of stagnation and ozone pollution}

The data and methods of Sect. 2 provide totals for individual summers of the number of cyclones passing through the southern climatological cyclone track (1948-2006 for Reanalysis 1, 1979-2006 for Reanalysis 2, 1980-2006 for NOAA weather maps), as well as the numbers of stagnation days (1980-1998) and ozone pollution days (1980-2006) in each $2.5^{\circ} \times 2.5^{\circ}$ grid square of the eastern US. We use the linear Pearson correlation coefficient to correlate these different variables on an interannual basis, and a Student's ttest to determine the significance of the correlation. To avoid the aliasing effects of long-term trends on the correlations, we removed linear trends from all individual time series that had significant trends at the $95 \%$ level. Long-term trends in ozone pollution days and mid-latitude cyclones will be discussed in Sect. 4.

Figure 7 (top panels) shows the interannual correlation between the number of stagnant days and the number of midlatitude cyclones derived from the reanalysis datasets. The correlation is generally significant and negative, indicating that less frequent mid-latitude cyclones in a given summer are associated with more frequent stagnant conditions. The negative correlation is strongest in the northeastern and midwestern US. This is because the cold fronts associated with mid-latitude cyclones generally do not extend to the southern US (see Fig. 1); moist convection and inflow from the Gulf of Mexico are a more important ventilation pathways in that region (Li et al., 2005).

The middle panels of Fig. 7 show the interannual correlation between the number of stagnant days and the number of ozone pollution days. There is strong positive correlation throughout the eastern US, with the exception of grid squares 


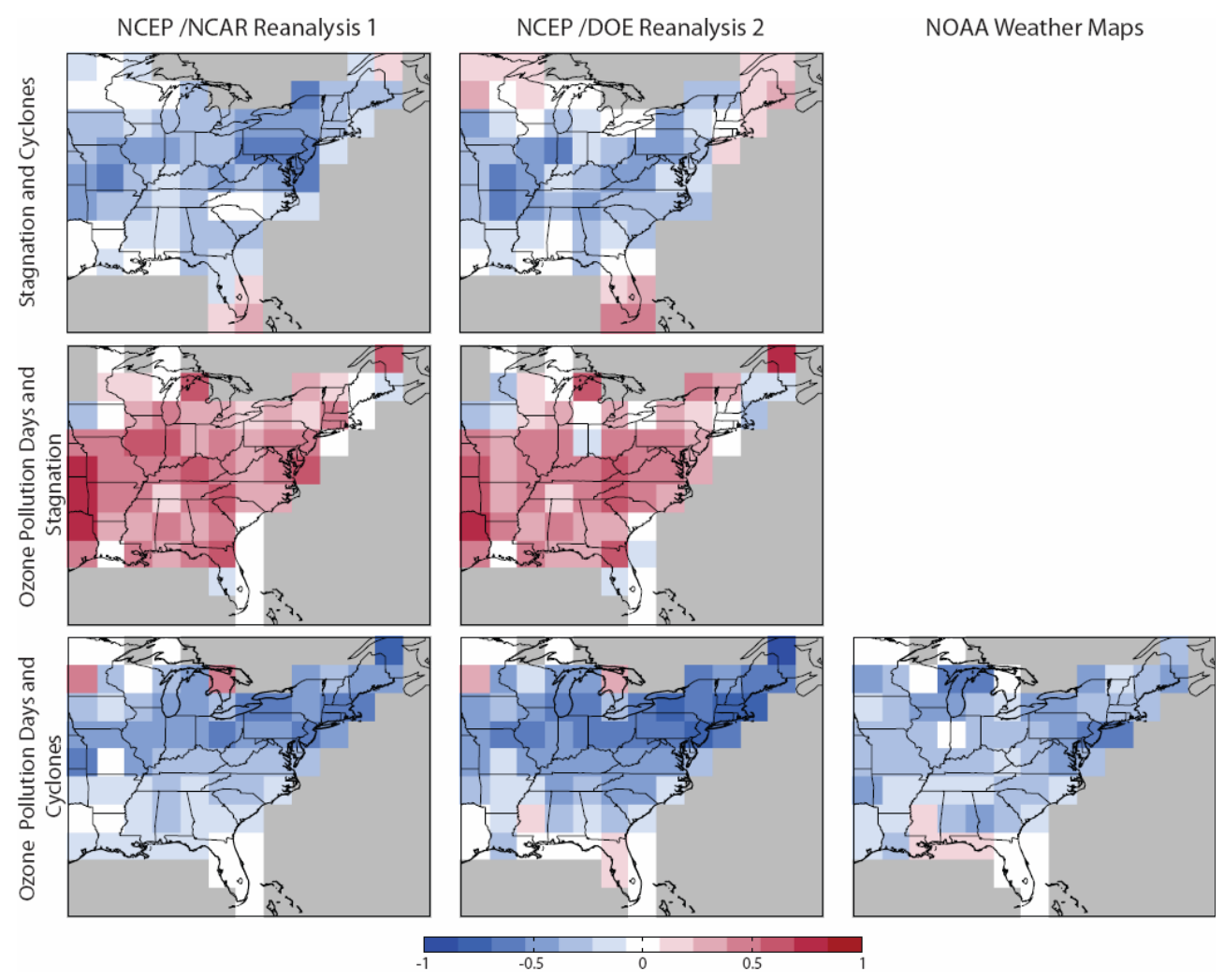

Fig. 7. Interannual correlation coefficients $(r)$ between the summer total numbers of mid-latitude cyclones, stagnation days, and ozone pollution days for 1980-1998 (top and middle panels) and 1980-2006 (bottom panels). The data are as described in Sect. 2. Numbers of cyclones are from the NCEP/NCAR Reanalysis 1 (left), the NCEP/DOE Reanalysis 2 (middle), and NOAA daily weather maps (right). Numbers of stagnation events are from the reanalyses only.

on the edge of the domain where wind direction (i.e., advection of pollution from upwind) is a more important predictor (Camalier et al., 2007).

The bottom panels of Fig. 7 show the interannual correlation between the number of ozone pollution days and the number of mid-latitude cyclones diagnosed from the reanalyses and from the NOAA weather maps. There is widespread negative correlation, stronger in the Midwest and Northeast than in the Southeast, consistent with the correlation of midlatitude cyclones and stagnation days seen in the reanalyses. We thus see that there is a clear cause-to-effect link, at least in the Midwest and Northeast, between mid-latitude cyclones, stagnation days, and ozone pollution days. The frequency of mid-latitude cyclones can be used as an interannual predictor of air quality. An important implication, from a climate change perspective, is that long-term trends in cyclone frequency may be expected to drive corresponding trends in air quality.

\section{Long-term trends in mid-latitude cyclone frequency and ozone pollution}

Reanalysis 1 and the NOAA weather maps feature a statistically significant decreasing trend of the number of cyclones in the southern climatological track between 1980 and $2006\left(-0.15 \mathrm{a}^{-1}\right.$ for Reanalysis $1,-0.14 \mathrm{a}^{-1}$ for the NOAA weather maps, both with $p<0.01$ ) (Fig. 4). Reanalysis 2 does not show a significant trend. Previously derived trends in mid-latitude cyclones have used the longer record of the Reanalysis 1 data (McCabe et al., 2001; Gulev et al., 2001; Geng and Sugi, 2001). The consistent trend that we see here between the NOAA daily weather maps and Reanalysis 1 provides important corroboration with the earlier studies.

We used the entire 1948-2006 extent of Reanalysis 1 to extend our trend analysis and compare to our GISS GCM simulations of the same period. Results in Fig. 8 show that the trend in Reanalysis 1 is confined to 1980-2006. The 1948-1980 period shows strong interannual variability but no trend. The GISS GCM simulation with historical changes in greenhouse gases, aerosols, and solar forcing shows a 1980-2006 decreasing trend in the number of cyclones frequency $\left(-0.16 \mathrm{a}^{-1}, p<0.01\right)$, consistent with Reanalysis 1 


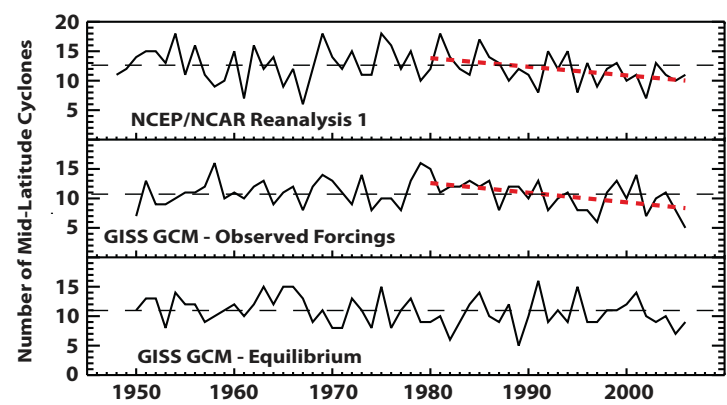

Fig. 8. Time series of the number of June-August mid-latitude cyclones tracking through $40^{\circ}-50^{\circ} \mathrm{N}, 70^{\circ}-90^{\circ} \mathrm{W}$ (the southern climatological cyclone track, see Fig. 3) for 1948-2006. Results from the NCEP/NCAR Reanalysis 1 (top) are compared to the GISS GCM 3 simulation including historical radiative forcings (middle), and to a GISS GCM 3 simulation in radiative equilibrium (bottom). The dashed lines show the long-term means for each time series to aid in visual trend identification. Red dashed lines show 1980-2006 regressions for the top two panels, where the trends are significant.

and the NOAA weather maps. It shows no trend prior to 1980, consistent with Reanalysis 1 . The GCM control simulation, conducted in radiative equilibrium, with greenhouse gas and aerosol concentrations and solar activity held at their 1950 levels, does not exhibit any significant trend over the 1950-2006 record. Thus we see that the 1980-2006 trend in cyclone frequency in the GISS GCM is driven by increase in greenhouse gases.

Figure 9 shows the trend in the number of ozone pollution days in the Northeast (defined as the New England and mid-Atlantic regions; see inset of Fig. 9). We focus on the Northeast because of its high number of ozone pollution days (Fig. 6) and the strong relationship of these pollution days to mid-latitude cyclone frequency (Fig. 7). The data in black represent the number of days over the course of the summer where one of the $2.5^{\circ} \times 2.5^{\circ}$ grid squares in the Northeast experienced a daily maximum 8 -h average ozone concentration exceeding $84 \mathrm{ppb}$. The number of ozone pollution days decreased at a rate of $0.84 \mathrm{a}^{-1}$ over the 1980 2006 period, a trend that can be credited to reduction of anthropogenic emissions of ozone precursors including nitrogen oxides $\left(\mathrm{NO}_{\mathrm{x}} \equiv \mathrm{NO}+\mathrm{NO}_{2}\right)$ and volatile organic compounds (VOCs) (Lin et al., 2001; Gégo et al., 2007). This improvement in ozone air quality occurred despite the concurrent decreasing trend of mid-latitude cyclones diagnosed from Reanalysis 1 (also shown in Fig. 9) and the daily NOAA daily weather maps. The detrended anomalies of the cyclone and ozone time series are strongly anticorrelated, as previously shown in Fig. 7; the corresponding scatterplot is shown in the bottom panel of Fig. 9. A reduced major axis linear regression of the detrended anomalies (Fig. 9) indicates a dependence of the number $n$ of ozone pollution days on the
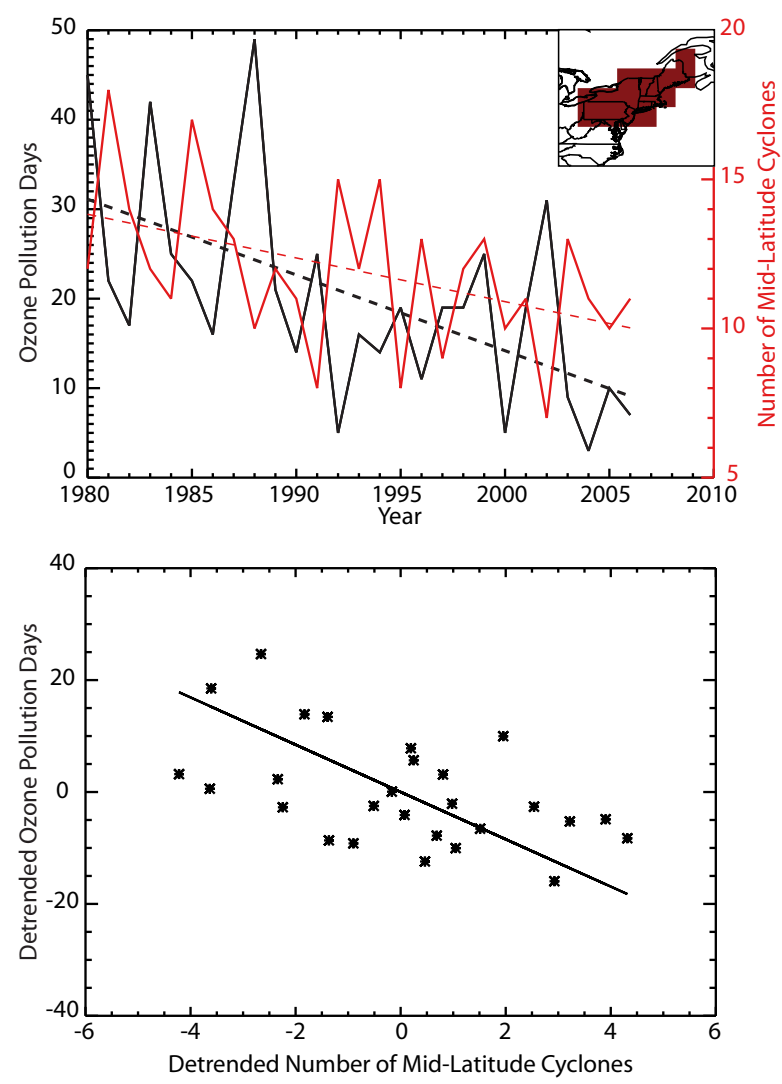

Fig. 9. Long-term trends and correlations of the number of ozone pollution days in the Northeast and the number of mid-latitudes cyclones in the southern climatological track. The top panel shows the summer 1980-2006 time series of the number of ozone pollution days (black) and the number of mid-latitude cyclones passing through the southern climatological track (red). Ozone pollution days are defined by the occurrence of a daily maximum 8 -h average ozone concentration exceeding $84 \mathrm{ppb}$ in one of the $2.5^{\circ} \times 2.5^{\circ}$ grid squares of the Northeast (inset). Cyclone data are from the NCEP/NCAR Reanalysis 1 and are as in Fig. 4. Dashed lines show the linear trends $(p<0.01)$. The bottom panel shows a scatterplot of the number of ozone pollution days $(n)$ vs. the number of midlatitude cyclones in the southern climatological track $(C)$, for individual years in the 1980-2006 record and after removal of the longterm linear trend. The line is the reduced major axis regression of the detrended data, which indicates a sensitivity $\partial n / \partial C=-4.2$.

number $C$ of mid-latitude cyclones, $\partial n / \partial C$, of -4.6 for the time series derived from daily weather maps and -4.2 for Reanalysis 1. This points to a major effect of 1980-2006 climate change on the observed ozone trends, as discussed below. 

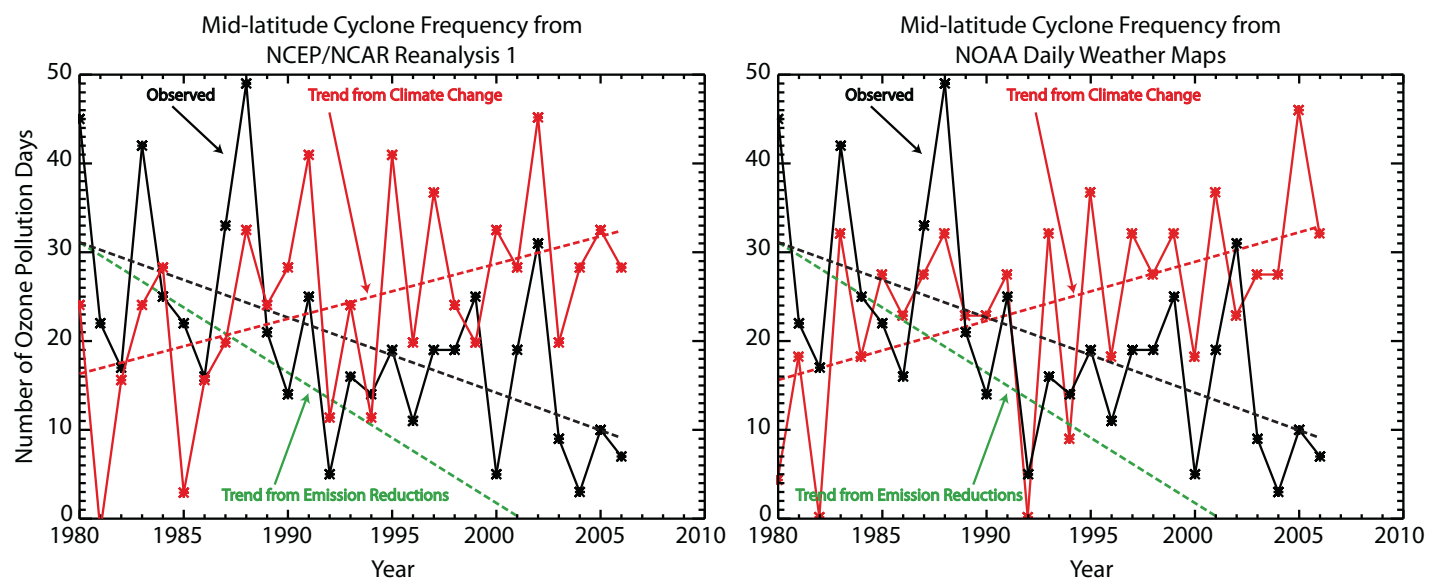

Fig. 10. 1980-2006 time series of the number of ozone pollution days in the northeast US (inset of Fig. 9). Observations are shown in black and are as in Fig. 9. The red line shows the number of ozone pollution days predicted from the number of mid-latitude cyclones in the NOAA weather maps (right) and in the NCEP/NCAR Reanalysis 1 (left) if anthropogenic emissions had not changed over the period (i.e., from the dependence $\partial n / \partial C$ derived in Sect. 4). Regression lines are shown and represent the observed trend ( $d n / d t$, in black) and the trend expected from climate change in the absence of change in anthropogenic emissions ([dn/dt $]_{E}$, in red). The green dashed line shows the trend expected from reductions in anthropogenic emissions in the absence of climate change, $[d n / d t]_{C}=d n / d t-[d n / d t]_{E}$.

\section{Effect of 1980-2006 climate change on ozone air qual- ity}

A long-term decreasing trend in mid-latitudes cyclones over the 1980-2006 period, as indicated by Reanalysis 1, the NOAA daily weather maps, and the GISS GCM simulation, would imply increasing stagnation and thus a more favorable meteorological environment for ozone pollution days. This could have offset some of the gains from decreases in anthropogenic emissions of ozone precursors, so that the return from emission controls would have been less than expected. Understanding such an effect is of great importance for the accountability of air quality policy (National Research Council, 2004).

We estimate here how the 1980-2006 trend in midlatitude cyclones as indicated by Reanalysis 1 and the NOAA weather maps may have affected the 1980-2006 trend in ozone air quality in the Northeast. The observed trend in the number of ozone pollution days per summer, $d n / d t$, is $-0.84 \mathrm{a}^{-1}$ (Fig. 9). Let us assume that this observed trend is driven by trends in emissions $E$ and in the number of cyclones $C$. We can then decompose the observed total derivative into partial derivatives:

$$
\frac{d n}{d t}=\left[\frac{d n}{d t}\right]_{E}+\left[\frac{d n}{d t}\right]_{C}
$$

with

$$
\left[\frac{d n}{d t}\right]_{E}=\frac{\partial n}{\partial E} \frac{\partial E}{\partial t}
$$

$$
\left[\frac{d n}{d t}\right]_{C}=\frac{\partial n}{\partial C} \frac{\partial C}{\partial t}
$$

where $[d n / d t]_{E}$ describes the trend due to changing emissions in the absence of climate change, and $[d n / d t]_{C}$ describes the trend due to climate change in the absence of change in emissions. We previously derived $\partial n / \partial C=-4.2$ from Reanalysis 1 ( -4.6 for the weather map analysis) and $\partial C / \partial t=-0.15 \mathrm{a}^{-1}\left(-0.14 \mathrm{a}^{-1}\right)$ in Sect. 4. Thus the trend in number of ozone pollution days due to climate change is $[d n / d t]_{C}=0.63 \mathrm{a}^{-1}\left(0.64 \mathrm{a}^{-1}\right)$. Replacing into Eq. (1) yields a trend in the number of ozone pollution days due to changing anthropogenic emissions, $[d n / d t]_{E}=-1.5 \mathrm{a}^{-1}$ $\left(-1.5 \mathrm{a}^{-1}\right)$. The analysis thus indicates that decreasing midlatitude cyclone frequency over the 1980-2006 period has offset the benefit of emission controls almost by half.

Figure 10 shows this result graphically for the cyclone trends from the NOAA weather maps and from Reanalysis 1. The time series of the number of ozone pollution days observed in the Northeast, as previously displayed in Fig. 9, is shown in black with the corresponding regression line $d n / d t=-0.84 \mathrm{a}^{-1}$. The time series predicted from the number of mid-latitude cyclones (Fig. 9) and the dependence, $\partial n / \partial C=-4.2(-4.6)$, derived in Sect. 4 is shown in red, with the corresponding regression line $[d n / d t]_{C}=0.63 \mathrm{a}^{-1}\left(0.64 \mathrm{a}^{-1}\right)$ representing the expected trend in ozone pollution days from climate change had emissions remained constant. We see that the frequency of ozone pollution days would have doubled over the 1980-2006 period as a result of climate change, were it not for concurrent decreases in anthropogenic emissions. The green line in 
Fig. 10 shows the trend in ozone pollution days that would have been realized from the decrease in anthropogenic emissions in the absence of climate change, i.e., $[d n / d t]_{E}=d n / d t-$ $[d n / d t]_{C}=-1.5 \mathrm{a}^{-1}\left(-1.5 \mathrm{a}^{-1}\right)$. We see that the expected number of ozone pollution days would have dropped to zero by 2001 , instead of remaining a significant problem (expected value of 10) by 2006 .

\section{Conclusions}

We showed that the frequency of mid-latitudes cyclones tracking across eastern North America in the $40^{\circ}-50^{\circ} \mathrm{N}$ latitudinal band (southern climatological track) is a strong predictor variable of the frequency of summertime pollution episodes in the eastern US. Cold fronts associated with these cyclones effectively ventilate the US boundary layer. We constructed cyclone tracks using the algorithm of Bauer and Del Genio (2006) applied to assimilated meteorological data from the NCEP/NCAR Reanalysis 1 (1948-2006) and the NCEP/DOE Reanalysis 2 (1979-2006); the two reanalyses agree closely in the locations and frequencies of cyclone tracks, and also agree well with cyclone statistics constructed directly from NOAA weather maps. Statistical analysis of 1980-2006 summer data shows large interannual variability in the number of cyclones in the southern climatological track (11.9 \pm 2.6 for Reanalysis 1$)$ and reveals strong negative interannual correlations between the number of cyclones and both the number of stagnation days and the number of ozone pollution days.

The frequency of mid-latitude cyclones in the $40^{\circ}-50^{\circ} \mathrm{N}$ band is of particular interest as a predictor variable for US air quality. First, it encapsulates in a single synoptic-scale variable the effects of known local predictor variables including temperature, wind speed, and solar radiation. Second, midlatitude cyclones are a feature of the general circulation of the atmosphere and are therefore amenable to trend analysis and prediction using GCMs. They can thus be used to diagnose and project the effects of climate change on US air quality.

Greenhouse warming is expected to decrease mid-latitude cyclone frequencies (Geng and Sugi, 2003; Yin, 2005; Lambert and Fyfe, 2006; Meehl et al., 2007), and such a decrease has been observed in climatological analyses of 1950-2000 data (Zishka and Smith, 1980; Gulev et al., 2001; McCabe et al., 2001, Wang et al., 2006). We examined more specifically the historical trend in the number of summer cyclones in the North American southern climatological track $\left(40^{\circ}-50^{\circ} \mathrm{N}\right)$ responsible for ventilating the eastern US. The NCEP/NCAR Reanalysis 1 and the NOAA daily weather maps both show significant decreasing trends for 1980-2006, with consistent slopes $\left(-0.15 \mathrm{a}^{-1}\right.$ and $-0.14 \mathrm{a}^{-1}$, respectively). The NCEP/DOE Reanalysis 2 shows no significant trend.
The NCEP/NCAR Reanalysis 1 starts in 1948. Analysis of the complete 1948-2006 record shows no cyclone trend prior to 1980. We compared this result to a transient-climate simulation for 1950-2006 with the GISS GCM 3 including historical greenhouse and aerosol forcing. This simulation shows a decrease in the number of cyclones for 1980-2006 $\left(-0.16 \mathrm{a}^{-1}\right)$, and no trend prior to 1980 , consistent with Reanalysis 1. A control GCM simulation for 1950-2006 with no greenhouse and aerosol forcing shows by contrast no trend over the whole period. The cyclone trend for the 1980-2006 period can thus be attributed to greenhouse forcing.

A 1980-2006 decrease in cyclone frequency as indicated by the NCEP/NCAR Reanalysis 1 and by the NOAA daily weather maps has important implications for the success and accountability of emission control strategies directed at improving US air quality. Our analysis of the surface ozone data indicates a decrease in the observed number of summertime ozone pollution days in the Northeast by $0.84 \mathrm{a}^{-1}$ over the 1980-2006 period, from an expected value of 31 (1980) to 10 (2006). This decrease can be credited to reduction of anthropogenic emissions, but we find that the benefit of these reductions may have been significantly offset by climate change. Taking the relationship between the number of summertime cyclones and the number of ozone pollution days from our correlation analysis, combined with the cyclone trend derived from either Reanalysis 1 or the NOAA daily weather maps, we deduce that the number of ozone pollution days would have doubled over the 1980-2006 period as a result of climate change if anthropogenic emissions had remained constant. Correcting the observed decrease of ozone pollution days for this climate trend, we find that the number of ozone pollution days would have dropped to an expected value of zero by 2001 in the absence of climate change.

We conclude from this analysis that the decrease in midlatitude cyclones over the 1980-2006 has offset half of the air quality gains in the Northeast US that should have been achieved from reduction of anthropogenic emissions over that period. This suggests that climate change has had already a major effect on the accountability of emission control strategies over the past 2-3 decades, preventing achievement of the ozone air quality standard. It demonstrates the potential of climate change to dramatically affect air quality on decadal scales relevant to air quality policy. Future attention to this issue is necessary in view of the consistent predictions from GCMs that 21st-century climate change will decrease the frequency of mid-latitude cyclones (Lambert and Fyfe, 2006).

Our analysis has focused on ozone air quality because of the availability of long-term records with high spatial density. We would expect mid-latitude cyclone frequency to also be a good predictor of particulate matter (PM) air quality, which is similarly affected by stagnation, but further analysis using PM observational records is necessary. Also, our analysis has focused on the eastern US, but similar analyses would be of 
value for western Europe and China, where mid-latitudes cyclones are also major agents for pollutant ventilation (Liu et al., 2003; Ordóñez et al., 2005). We have found in the eastern US that although mid-latitude cyclone frequency is a good predictor of pollution episodes in the Northeast and Midwest, it is less effective in the South. Other large-scale meteorological metrics should be sought there and in the West to enable assessments of the effect of climate change on air quality.

Acknowledgements. This work was supported by the Electric Power Research Institute (EPRI), the Environmental Protection Agency - Science To Achieve Results (EPA-STAR) Program, and an EPA-STAR Graduate Fellowship to Eric Leibensperger. The EPA has not officially endorsed this publication and the views expressed herein may not reflect those of the EPA. We thank Mike Bauer for supplying and supporting the cyclone tracking procedure and Shiliang Wu for helpful discussions.

Edited by: A. Pszenny

\section{References}

Bauer, M. and Del Genio, A. D.: Composite analysis of winter cyclones in a GCM: Influence on climatological humidity, J. Clim., 19, 1652-1672, 2006.

Bloomfield, P., Royle, J. A., Steinberg, L. J., and Yang, Q.: Accounting for meteorological effects in measuring urban ozone levels and trends, Atmos. Environ., 30, 3067-3077, 1996.

Camalier, L., Cox, W., and Dolwick, P.: The effects of meteorology on ozone in urban areas and their use in assessing ozone trends, Atmospheric Environment, 41, 7127-7137, 2007.

Chandler, M. and Jonas, J.: Atlas of extratropical storm tracks, http: //data.giss.nasa.gov/stormtracks/, 1999.

Cooper, O. R., Moody, J. L., Parrish, D. D., Trainer, M., Ryerson, T. B., Holloway, J. S., Hubler, G., Fehsenfeld, F. C., Oltmans, S. J., and Evans, M. J.: Trace gas signatures of the airstreams within North Atlantic cyclones: Case studies from the North Atlantic Regional Experiment (NARE 1997) aircraft intensive, J. Geophys. Res.-Atmos., 106, 5437-5456, 2001.

Dickerson, R. R., Doddridge, B. G., Kelley, P., and Rhoads, K. P.: Large scale pollution of the atmosphere over the remote Atlantic Ocean - Evidence from Bermuda, J. Geophys. Res.-Atmos., 100, 8945-8952, 1995.

Gégo, E., Porter, P. S., Gilliland, A., and Rao, S. T.: Observationbased assessment of the impact of nitrogen oxides emissions reductions on ozone air quality over the eastern United States, J. Appl. Meteorol. Climatol., 46, 994-1008, 2007.

Geng, Q. Z. and Sugi, M.: Variability of the North Atlantic cyclone activity in winter analyzed from NCEP-NCAR reanalysis data, J. Clim., 14, 3863-3873, 2001.

Geng, Q. Z. and Sugi, M.: Possible change of extratropical cyclone activity due to enhanced greenhouse gases and sulfate aerosols - Study with a high-resolution AGCM, J. Clim., 16, 2262-2274, 2003.

Gulev, S. K., Zolina, O., and Grigoriev, S.: Extratropical cyclone variability in the Northern Hemisphere winter from the NCEP/NCAR reanalysis data, Clim. Dynam., 17, 795-809, 2001.
Hansen, J., Fung, I., Lacis, A., Rind, D., Lebedeff, S., Ruedy, R., Russell, G., and Stone, P.: Global climate changes as forecast by Goddard Institute for Space Studies 3-Dimensional model, J. Geophys. Res.-Atmos., 93, D8, 9341-9364, 1988.

Hansen, J., Sato, M., Nazarenko, L., Ruedy, R., Lacis, A., Koch, D., Tegen, I., Hall, T., Shindell, D., Santer, B., Stone, P., Novakov, T., Thomason, L., Wang, R., Wang, Y., Jacob, D., Hollandsworth, S., Bishop, L., Logan, J., Thompson, A., Stolarski, R., Lean, J., Willson, R., Levitus, S., Antonov, J., Rayner, N., Parker, D., and Christy, J.: Climate forcings in Goddard Institute for Space Studies SI2000 simulations, J. Geophys. Res.-Atmos, 107, D18, doi:10.1029/2001JD001143, 2002.

Harnik, N. and Chang, E. K. M.: Storm track variations as seen in radiosonde observations and reanalysis data, J. Clim., 16, 480495, 2003.

Hegarty, J., Mao, H., and Talbot, R.: Synoptic controls on summertime surface ozone in the northeastern United States, J. Geophys. Res.-Atmos., 112, D14306, doi:10.1029/2006JD008170, 2007.

$\mathrm{Hu}, \mathrm{Q}$., Tawaye, Y., and Feng, S.: Variations of the Northern Hemisphere atmospheric energetics: 1948-2000, J. Clim., 17, 19751986, 2004.

Kalnay, E., Kanamitsu, M., Kistler, R., Collins, W., Deaven, D., Gandin, L., Iredell, M., Saha, S., White, G., Woollen, J., Zhu, Y., Chelliah, M., Ebisuzaki, W., Higgins, W., Janowiak, J., Mo, K. C., Ropelewski, C., Wang, J., Leetmaa, A., Reynolds, R., Jenne, R., and Joseph, D.: The NCEP/NCAR 40-year reanalysis project, B. Am. Meteorol. Soc., 77, 437-471, 1996.

Kanamitsu, M., Ebisuzaki, W., Woollen, J., Yang, S. K., Hnilo, J. J., Fiorino, M., and Potter, G. L.: NCEP-DOE AMIP-II reanalysis (R-2), B. Am. Meteorol. Soc., 83, 1631-1643, 2002.

Kistler, R., Kalnay, E., Collins, W., Saha, S., White, G., Woollen, J., Chelliah, M., Ebisuzaki, W., Kanamitsu, M., Kousky, V., van den Dool, H., Jenne, R., and Fiorino, M.: The NCEP-NCAR 50year reanalysis: Monthly means CD-ROM and documentation, B. Am. Meteorol. Soc., 82, 247-267, 2001.

Korshover, J. and Angell, J. K.: A review of air stagnation cases in the eastern United States during 1981 - Annual Summary, Mon. Weather Rev., 110, 1515-1518, 1982.

Lambert, S. J. and Fyfe, J. C.: Changes in winter cyclone frequencies and strengths simulated in enhanced greenhouse warming experiments: results from the models participating in the IPCC diagnostic exercise, Clim. Dynam. 26, 713-728, 2006.

Li, Q. B., Jacob, D. J., Park, R., Wang, Y. X., Heald, C. L., Hudman, R., Yantosca, R. M., Martin, R. V., and Evans, M.: North American pollution outflow and the trapping of convectively lifted pollution by upper-level anticyclone, J. Geophys. Res.-Atmos. 110, D10301, doi:10.1029/2004JD005039, 2005.

Lin, C. Y. C., Jacob, D. J., and Fiore, A. M.: Trends in exceedances of the ozone air quality standard in the continental United States, 1980-1998, Atmos. Environ., 35, 3217-3228, 2001.

Lin, J.-T., Patten, K. O., Hayhoe, K., Liang, X.-Z., and Wuebbles, D. J.: Effects of future climate and biogenic emissions changes on surface ozone over the United States and China, J. Appl. Meteorol. Climatol., 47, 1888-1909, 2008.

Liu, H. Y., Jacob, D. J., Bey, I., Yantosca, R. M., Duncan, B. N., and Sachse, G. W.: Transport pathways for Asian pollution outflow over the Pacific: Interannual and seasonal variations, J. Geophys. Res.-Atmos., 108, D20, 2003. 
Logan, J. A.: Ozone in rural areas of the United States, J. Geophys. Res.-Atmos., 94, D6, 8511-8532, 1989.

McCabe, G. J., Clark, M. P., and Serreze, M. C.: Trends in Northern Hemisphere surface cyclone frequency and intensity, J. Clim., 14, 2763-2768, 2001.

Meehl, G. A., Stocker, T. F., Collins, W. D., Friedlingstein, P., Gaye, A. T., Gregory, J. M., Kitoh, A., Knutti, R., Murphy, J. M., Noda, A., Raper, S. C. B., Watterson, I. G., Weaver, A. J., and Zhao, Z.-C.: Global Climate Projections, in: Climate Change 2007: The Physical Science Basis, edited by: Solomon, S., Qin, D., Manning, M., Chen, Z., Marquis, M., Averyt, K. B., Tignor, M., and Miller, H. L., Cambridge University Press, Cambridge, UK, 747-846, 2007.

Merrill, J. T. and Moody, J. L.: Synoptic meteorology and transport during the North Atlantic Regional Experiment (NARE) intensive: Overview, J. Geophys. Res.-Atmos., 101, 28 903-28 921, 1996.

Mickley, L. J., Jacob, D. J., Field, B. D., and Rind, D.: Effects of future climate change on regional air pollution episodes in the United States, Geophys. Res. Lett., 31, L24103, doi:10.1029/2004GL021216, 2004.

Murazaki, K. and Hess, P.: How does climate change contribute to surface ozone change over the United States?, J. Geophys. Res.Atmos., 111, D05301, doi:10.1029/2005JD005873, 2006.

National Research Council: Air Quality Management in the United States, National Academies Press, Washington, DC, 2004.

Ordóñez, C., Mathis, H., Furger, M., Henne, S., Huglin, C., Staehelin, J., and Prevot, A. S. H.: Changes of daily surface ozone maxima in Switzerland in all seasons from 1992 to 2002 and discussion of summer 2003, Atmos. Chem. Phys., 5, 1187-1203, 2005 ,

http://www.atmos-chem-phys.net/5/1187/2005/.

Owen, R. C., Cooper, O. R., Stohl, A., and Honrath, R. E.: An analysis of the mechanisms of North American pollutant transport to the central North Atlantic lower free troposphere, J. Geophys. Res.-Atmos., 111, D23S58, doi:10.1029/2006JD007062, 2006.

Paciorek, C. J., Risbey, J. S., Ventura, V., and Rosen, R. D.: Multiple indices of Northern Hemisphere cyclone activity, winters 1949-1999, J. Clim., 15, 1573-1590, 2002.

Racherla, P. N. and Adams, P. J.: The response of surface ozone to climate change over the Eastern United States, Atmos. Chem. Phys., 8, 871-885, 2008,

http://www.atmos-chem-phys.net/8/871/2008/.
Rind, D., Lerner, J., Jonas, J., and McLinden, C.: Effects of resolution and model physics on tracer transports in the NASA Goddard Institute for Space Studies general circulation models, J. Geophys. Res.-Atmos., 112, D09315, doi:10.1029/2006JD007476, 2007.

Tagaris, E., Manomaiphiboon, K., Liao, K. J., Leung, L. R., Woo, J. H., He, S., Amar, P., and Russell, A. G.: Impacts of global climate change and emissions on regional ozone and fine particulate matter concentrations over the United States, J. Geophys. Res.-Atmos., 112, D14312, doi:10.1029/2006JD008262, 2007.

Thompson, M. L., Reynolds, J., Cox, L. H., Guttorp, P., and Sampson, P. D.: A review of statistical methods for the meteorological adjustment of tropospheric ozone, Atmos. Environ., 35, 617630, 2001.

Vukovich, F. M.: Regional scale boundary layer ozone variations in the eastern United States and their association with meteorological variations, Atmos. Environ., 29, 2259-2273, 1995.

Wang, J. X. L. and Angell, J. K.: Air Stagnation Climatology for the United States, NOAA/Air Resource Laboratory ATLAS No. $1,1999$.

Wang, X. L., Wan, W. H., and Swail, V. R.: Observed changes in cyclone activity in Canada and their relationships to major circulation regimes, J. Clim., 19, 896-915, 2006.

Whittaker, L. M. and Horn, L. H.: Geographical and seasonal distribution of North American cyclogenesis, 1958-1977, Mon. Weather Rev., 109, 2312-2322, 1981.

Wu, S., Mickley, L. J., Leibensperger, E. M., Jacob, D. J., Rind, D., and Streets, D. G.: Effects of 2000-2050 global change on ozone air quality in the United States, J. Geophys. Res.-Atmos., 113, D06302, doi:10.1029/2007JD008917, 2008.

Yin, J. H.: A consistent poleward shift of the storm tracks in simulations of 21 st century climate, Geophys. Res. Lett., L18701, doi:10.1029/2005GL023684, 2005.

Zheng, J., Swall, J. L., Cox, W. M., and Davis, J. M.: Interannual variation in meteorologically adjusted ozone levels in the eastern United States: A comparison of two approaches, Atmos. Environ., 41, 705-716, 2007.

Zishka, K. M., and Smith, P. J.: The climatology of cyclones and anticyclones over North America and surrounding ocean environs for January and July, 1950-1977, Mon. Weather Rev., 108, 387-401, 1980. 